\title{
THERMORESISTIVE THIN FILM FLOW SENSOR
}

\author{
T.M. BERLICKI, E. MURAWSKI, S.J. OSADNIK, \\ and E.L. PROCIÒW \\ Institute of Electron Technology Technical University of Wroclaw, Janiszewskiego \\ 11/17; 50-372 WROCLAW, POLAND \\ (Received April 21, 1988; in final form May 18, 1988)
}

Some technological aspects and basic parameters of nickel thin film gas flow sensors are presented. Thermal conditions of sensors are described by the mechanisms of heat transfer. Typical characteristics measured during the sensor operation are given.

\section{INTRODUCTION}

In order to construct thermoresistive thin film elements, platinum or nickel are most frequently used. Being highly resistant to corrosion, platinum is often utilized for this purpose. Elements made of platinum have good stability and can be used to operate over a wide range of temperatures. Nickel as a material used for constructing thin film thermoresistors has also a number of advantages. It is much cheapter than platinum and, at the same time, its temperature coefficient of resistance (TCR) is twice as high as that of platinum. The maximum temperature of the stable operation of nickel films is much lower in comparison with that of platinum, but it may be increased by using an appropriate protective film. Moreover, nickel films exhibit good solderability and weldability.

In this work the authors undertook the task of discovering whether it is possible to use thin film nickel thermoresistors as flow sensors. These are sensors which utilize the temperature changes of a resistive element subjected to the cooling action of the flowing gas. Knowledge of electrical and thermal parameters, resistance and TCR, thermal resistance and sensitivity to the gas flow rate is essential for optimum design of these elements. The sensor is loaded with power 
which causes its temperature to increase from $500 \mathrm{~K}$ to $600 \mathrm{~K}$. Therefore the resistive element should be operationally reliable at an increased temperature in a parametric sense as well as increase to catastrophic failure.

\section{CONSTRUCTION AND PREPARATION OF THE SENSOR}

Substrates for sensors were made of Corning 7059 glass foil $120 \mu \mathrm{m}$ to $160 \mu \mathrm{m}$ thick. The binary film system $\mathrm{NiCr}-\mathrm{Ni}$ was vacuum deposited onto the foil. Meander-formed thermoresistors were obtained with a photolithographic method. The thermoresistors were separated into chips, and gold wire leads $20 \mu \mathrm{m}$ to $100 \mu \mathrm{m}$ in diameter were bonded to the contact pads with thermocompression techniques. Next, a $5 \mu \mathrm{m}$ thick protective film of $\mathrm{SiOx}$ was vacuum evaporated onto the surfaces of the chips. In order to stabilize the parameters the sensors were annealed at a temperature of $623 \mathrm{~K}$ for 20 hours. The appearance of the sensor is illustrated in Figure 1.

\section{RESISTANCE AND TCR}

The thickness of the nickel films used by the authors was over $100 \mathrm{~nm}$. In this range of thickness the size effect is hardly significant. The crystalline structure of the film has a dominating influence on the electrical parameters. It may be assumed that the average size of grains is proportional to the film thickness. Thus there is a close dependence of the resistivity and TCR values on the thickness of the nickel film. On the base of the Mayadas-Shatzkes model of the scat-

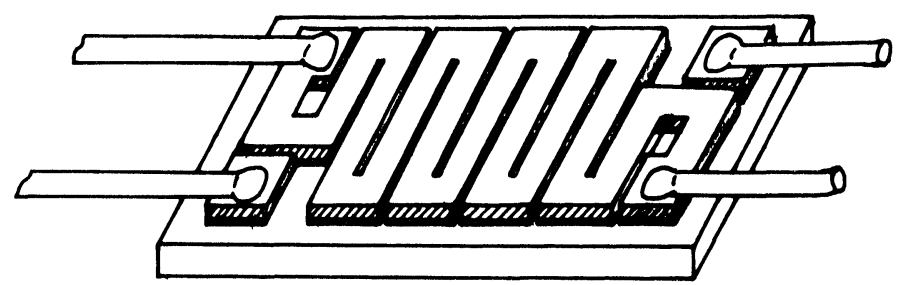

FIGURE 1 Construction of the thermoresistive thin film flow sensor. 
tering process on the grain boundaries ${ }^{1,2}$ it is possible to make an approximating assumption that

$\varrho_{\mathrm{F}}=\varrho_{\mathrm{B}}\left(1+\frac{\mathrm{A}_{1}}{\mathrm{~d}}\right)$

$\mathrm{TCR}_{\mathrm{F}}=\mathrm{TCR}_{\mathrm{B}}\left(1-\frac{\mathrm{A}_{2}}{\mathrm{~d}}\right)$

where $\varrho_{\mathrm{F}}$ and $\varrho_{\mathrm{B}}$ is the resistivity of the film and of the bulk material, $\mathrm{TCR}_{\mathrm{F}}$ and $\mathrm{TCR}_{\mathrm{B}}$ are the temperature coefficients of resistance of film and of bulk material respectively, $d$ is the film thickness, $A_{1}$ and $A_{2}$ are constants.

Figures 2 and 3 show the characteristics of $\varrho_{F}$ and $\mathrm{TCR}_{\mathrm{F}}$ as a functions the film thickness which were obtained for nickel films. These dependences are presented in the $\varrho_{\mathrm{F}}$ v.s. $\frac{1}{\mathrm{~d}}$ and TCR v.s. $\frac{1}{d}$ coordinates to obtain nearly straight lines. TCR $_{F}$, similarly to that of bulk material, has no constant value but changes with temperature. These changes are approximately linear (Figure 4).

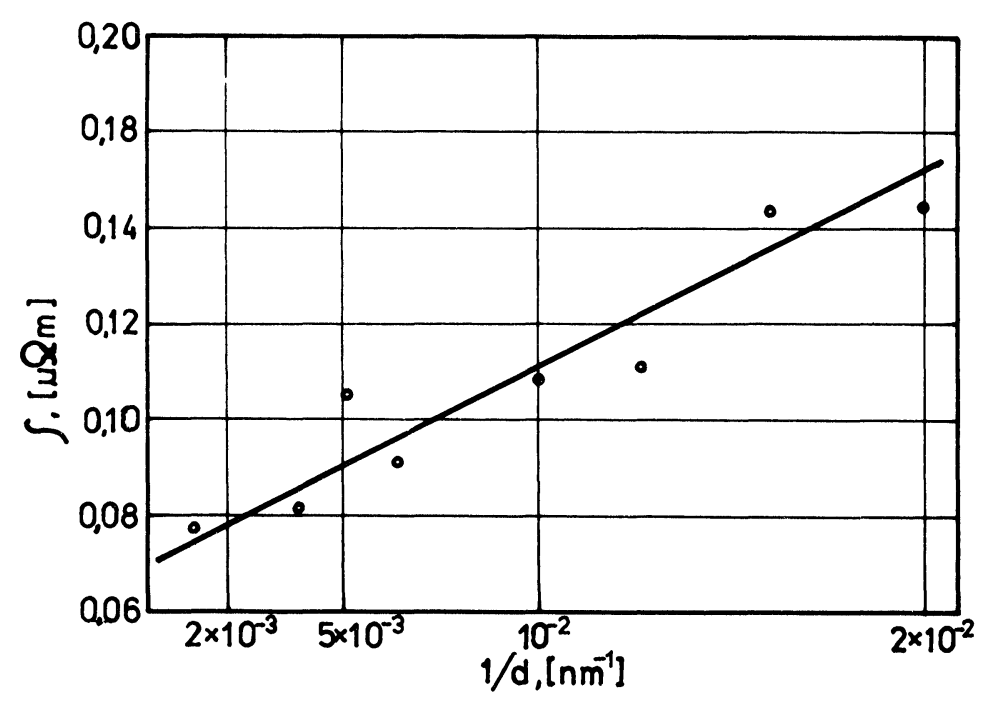

FIGURE 2 Resistivity v.s. film thickness for the thin nickel film. 


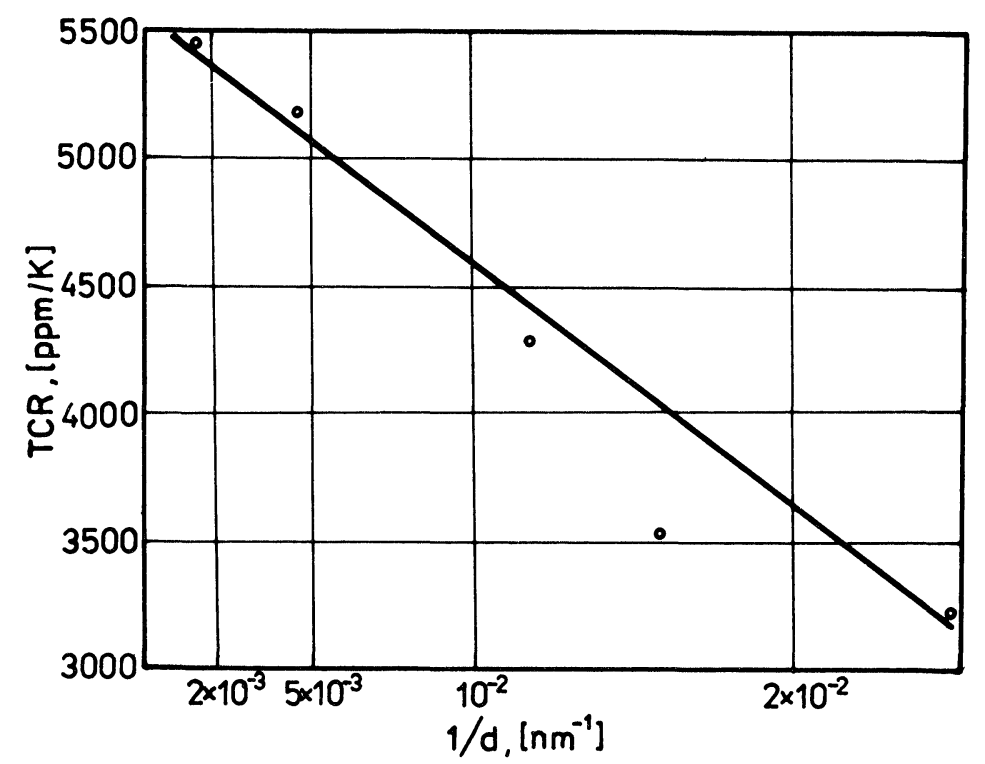

FIGURE 3 Film thickness versus TCR for a thin nickel film.

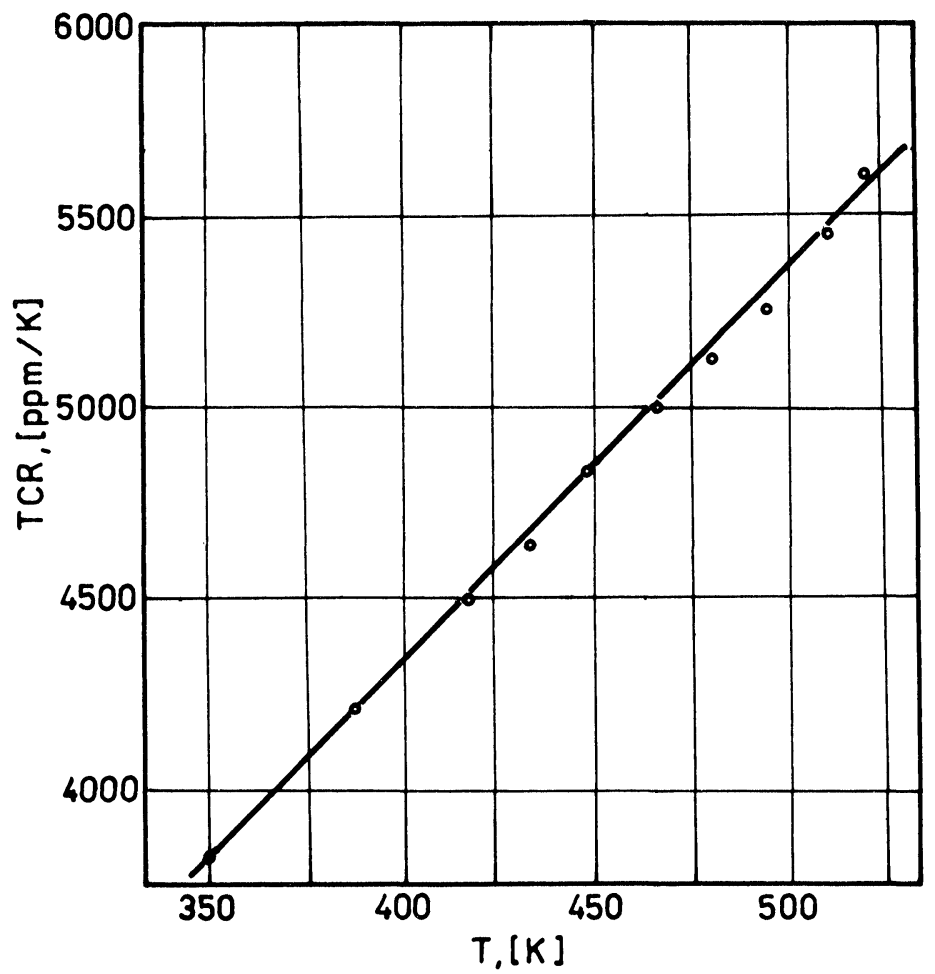

FIGURE 4 Changes in TCR of the sensor with temperature. 
The characteristic differs from that obtained for bulk nickel in the form of a wire, attributable first of all to the increased resistivity of the film, which is caused by additional scattering on the grain boundaries.

\section{THERMAL PARAMETERS}

The temperature and power characteristics of sensors depend on the mechanisms of heat transfer. The heat is carried away into the ambient through radiation, flowing - round gas, as well as through the conductivity of the glass substrate and leads. The schematic diagram of these mechanisms is presented in Figure 5a. Such a scheme can be modelled by a circuit of resistors as presented in Figure $5 \mathrm{~b}$. These resistors represent the mechanisms of heat transfer in the respective sections of the sensor. By introducing appropriate values for respective components it is possible to approximate a substitute system with three resistors (Figure $5 \mathrm{c}$ ).

The thermal resistance $\mathrm{Rg}$, is the result of heat transmission from the sensor to the surrounding gas. Its value depends on the sensor gas heat transfer as well as on radiation. Changes of this component result from the gas flow conditions. The resistance $R_{s}$ depends on the heat flow through the glass towards the leads. Its value can be determined from the relationship:

$\mathrm{R}_{\mathrm{s}}=\frac{1}{\lambda_{\mathrm{s}}} \cdot \frac{\mathrm{l}_{\mathrm{eff}}}{\mathrm{h} \cdot \mathrm{w}_{\mathrm{eff}}}$

where $\lambda_{s}$ is the thermal conductivity of glass, $h$ is the thickness of substrate, $l_{\text {eff }}$ and $\mathrm{w}_{\text {eff }}$ are length and width of the heat flux path.

The effective width $w_{\text {eff }}$ is smaller than that of the substrate $\mathrm{W}$ due to the contraction of the heat flux path at leads. The effective length $l_{\text {eff }}$ depending on the configuration of leads and their cross-section ranges from $1 / 41$ to $1 / 81$. The resistance $R_{s}$ is of distributed nature. The values $\mathrm{w}_{\text {eff }}$ and $\mathrm{l}_{\mathrm{eff}}$ result from the distribution of particular resistances.

The thermal resistance $R_{d}$ is a parameter connected with the thermal conductivity of leads

$R_{d}=\frac{1}{\lambda_{d}} \cdot \frac{L}{S_{d}}$ 
(a)

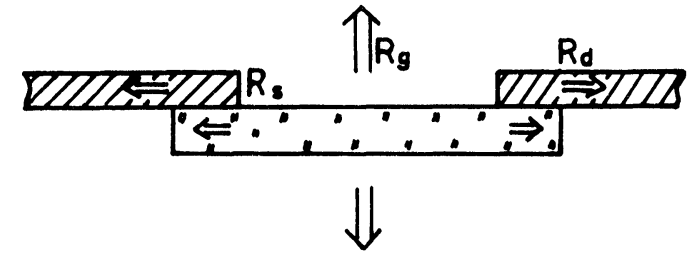

(b)

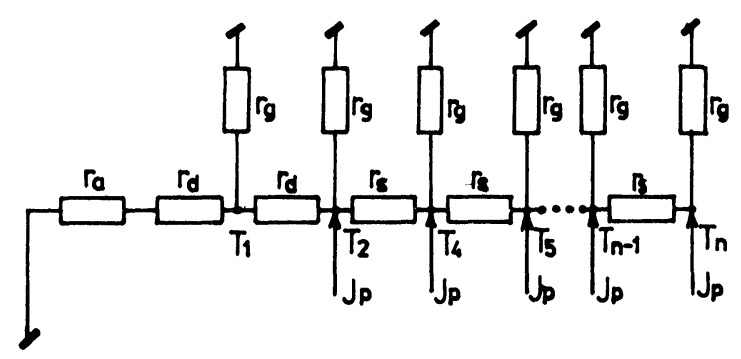

(c)

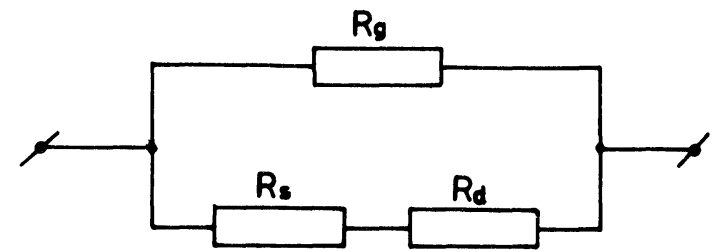

FIGURE 5 Schematic diagram of the thermal resistance for the sensor: a) Model of heat transfer, b) Substitute circuit of resistors, c) Equivalent system of three resistors.

where $\lambda_{\mathrm{d}}$ is the thermal conductivity of leads, $L$ and $S_{d}$ are length and cross-section of leads.

The total thermal resistance $R_{T}$ was measured in the case of natural convection. A decreasing dependence of the value $R_{T}$ on the dissipated power was obtained (Figure 6). The thermal conductivity of the applied glass increases along with the increase in temperature ${ }^{3}$ whereas the conductivity of leads made of gold wire decreases. Thus the temperature effects compensate one another to some extent. The coefficient of heat transfer through convection increases with the increase in temperature ${ }^{4}$. The overall effect of all the factors causes the thermal resistance to decrease as the temperature increases. For the sensor of size $1 \times 2 \times 0.14 \mathrm{~mm}^{3}$ there are following components 


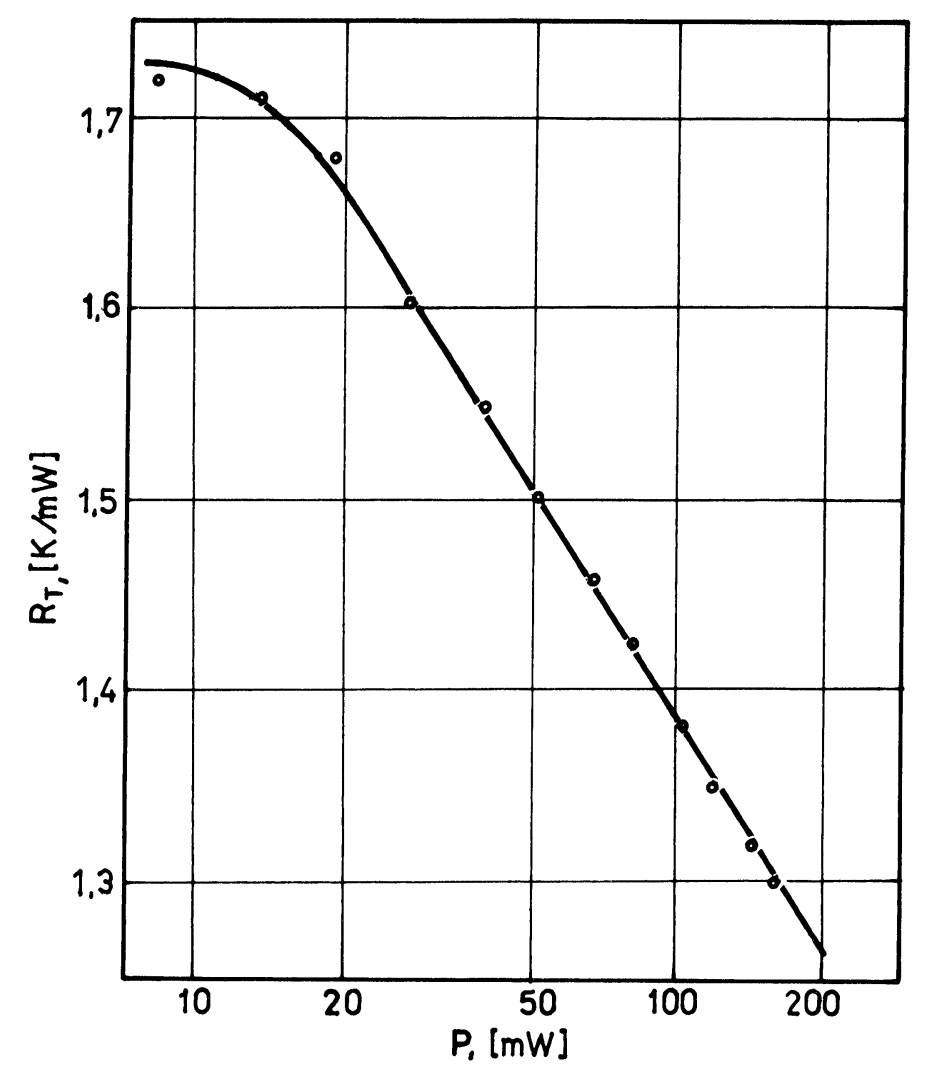

FIGURE 6 Thermal resistance as a function of power dissipated in the sensor.

of the thermal resistance: $R_{g}=2.5 \mathrm{~K} / \mathrm{mW}, R_{s}=2 \mathrm{~K} / \mathrm{mW}$ and $R_{d}=$ $0.7 \mathrm{~K} / \mathrm{mW}$. A change of the cooling conditions results in changes of the component $\mathrm{R}_{\mathrm{g}}$. When the dimensions of the substrate are changed, particularly its thickness, the value of component $R_{s}$ changes as well. If the thickness of the substrate is increased then the value $R_{s}$ decreases and so does the overall resistance $R_{T}$ (Figure 7). The same applies to the resistance of leads $R_{d}$. When their crosssection decreases, the value of $R_{d}$ increases and the overall value of $R_{T}$ increases as well (Figure 8).

For operational reasons the power sensitivity is the essential parameter here. It is expressed by the formula: 


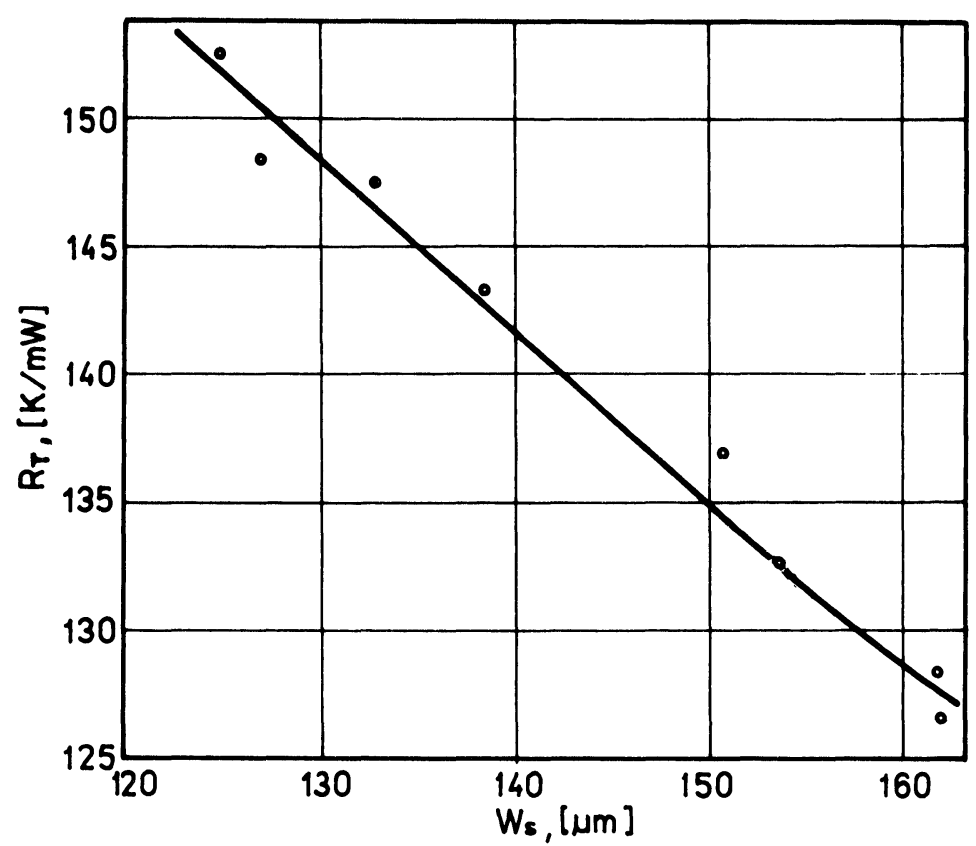

FIGURE 7 Thermal resistance v.s. thickness of the sensor.

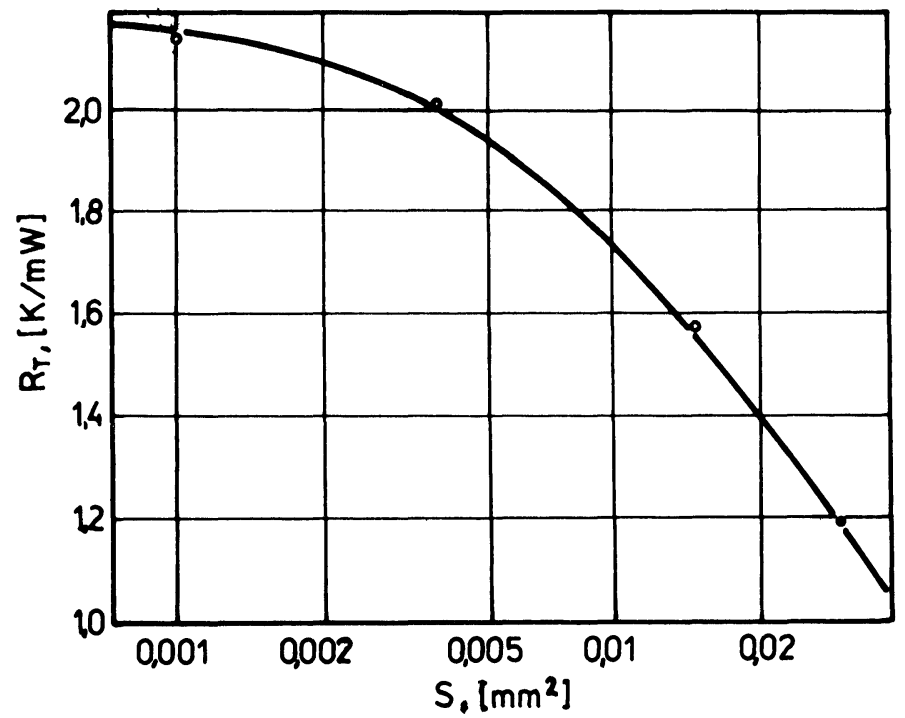

FIGURE 8 Thermal resistance as a function of the cross-section of the leads. 
$\mathrm{S}=\frac{\Delta \mathrm{R}}{\mathrm{R}} / \mathrm{P}$

where $P$ is the power and $\Delta R / R$ is a relative change of resistance resulting from the temperature increase due to the applied power $P$.

The sensitivity $S$ is expressed by the equation

$S=T C R \cdot R_{T}$

The parameter TCR displays an approximately linear increase with temperature, whereas an approximately linear decrease can be observed in the case of $R_{T}$.

In the range of temperatures and power being studied the sensitivity increases with an increase of temperature or power.

Figure 9 presents the dependence of the sensitivity $S$ on power applied for different cross-sections of leads. The effect of the gas flow rate is manifested by a decrease in the component of $R_{g}$. The variation of the ratio of the power removed to the emitted power $P_{o}$ as a result of natural convection was measured as a function of the air

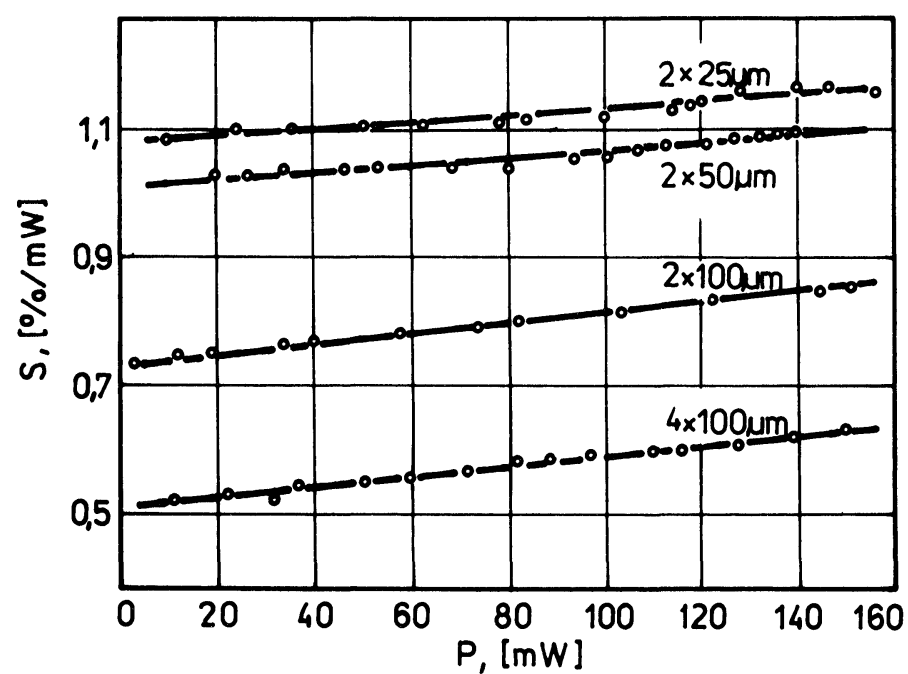

FIGURE 9 Power sensitivity as a function of the power applied to the sensor for various diameters of lead. 


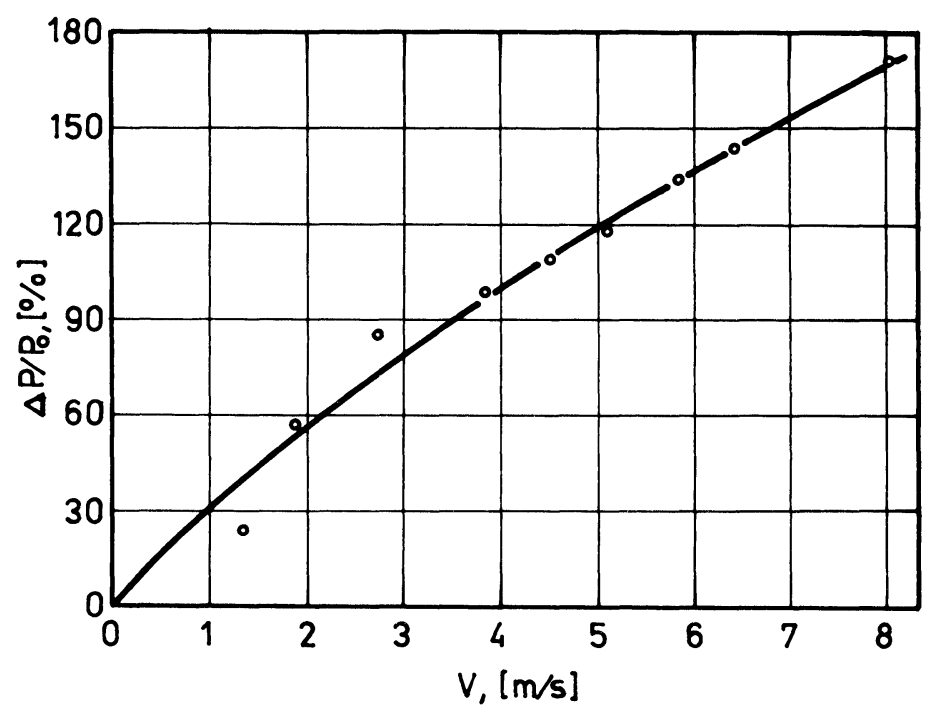

FIGURE 10 Variation of relative power with air-flow rate.

flow rate (Figure 10). A constant temperature of the sensor $563 \mathrm{~K}$ was assumed.

Heat removal from the sensor is dependent on its temperature. That is why the thermal parameters of the sensor will also depend on temperature. The variation of the changes of power removed $\Delta \mathrm{P} / \mathrm{P}_{\mathrm{o}}$, as a function of temperature at the air flow rate $\mathrm{V}=2.7 \mathrm{~m} / \mathrm{s}$ is presented in Figure 11. A decrease in the value of power changes is observed. At temperatures up to $573 \mathrm{~K}$ it results from the dependence of the heat transfer coefficient on temperature, whereas at the temperature of over $573 \mathrm{~K}$ additional changes result from the effect of heat transfer caused by radiation. If a constant voltage supply to the sensor is assumed then at the given temperature the changes of power (or current) resulting from the gas flow exhibit their maximum (Figure 12). This temperature, depending on the construction of the sensor, was from $523 \mathrm{~K}$ to $573 \mathrm{~K}$ at the flow rate of $2.7 \mathrm{~m} / \mathrm{s}$.

\section{STABILITY AND RELIABILITY}

The stability of TCR and of the sensor resistance with time dependent mainly on two mechanisms: the growth of grain sizes and 


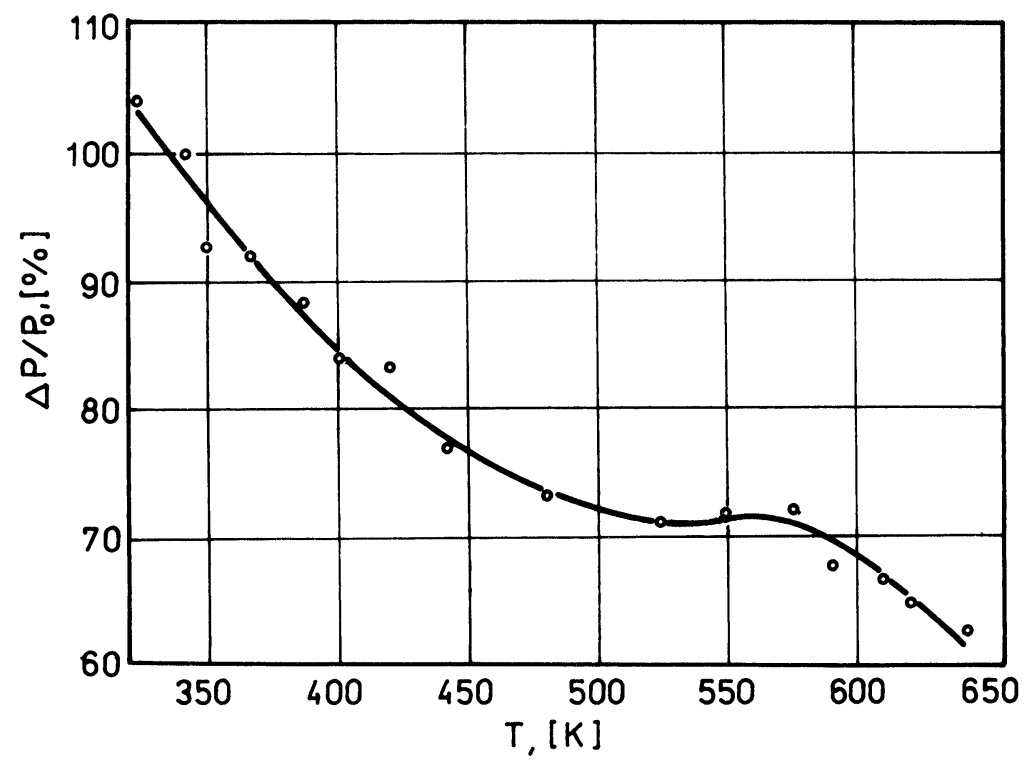

FIGURE 11 Sensitivity of sensor v.s. temperature.

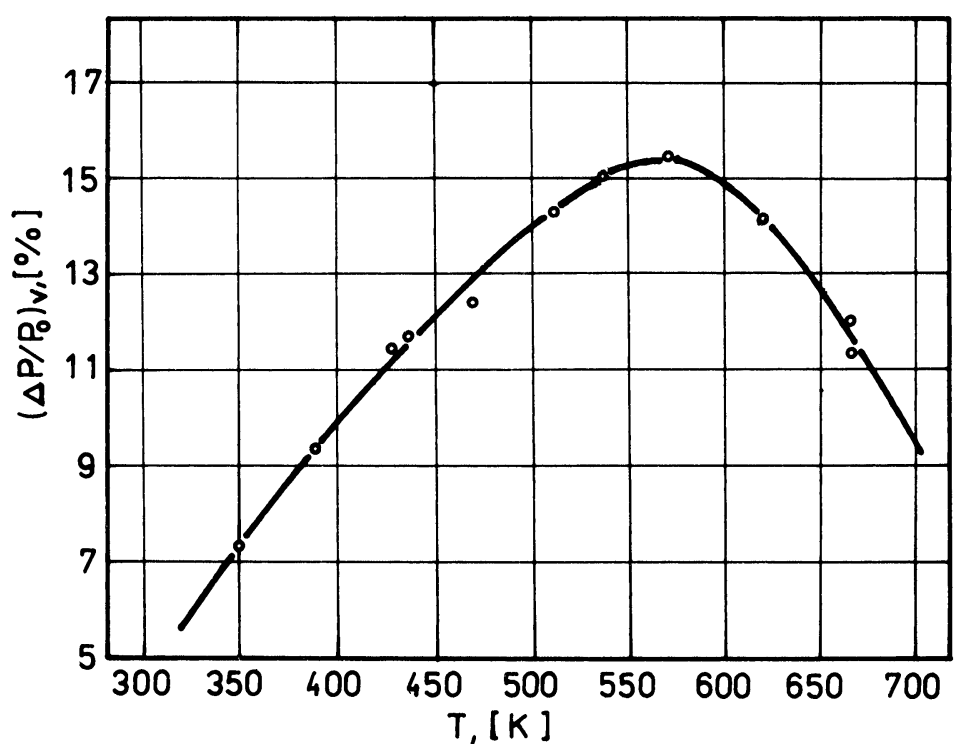

FIGURE 12 Changes in sensitivity of the sensor for a constant voltage supply as a function of temperature. 
the diffusion of chromium from the $\mathrm{NiCr}$ film into the nickel film. The recrystallization leading to an increase in the dimensions of grains causes the electron free path increase. This is manifested by a decrease in the resistance as well as by an increase of the coefficient of $\mathrm{TCR}^{5}$. The process of grain dimension increase in time is described by the empirical equation ${ }^{6,7}$

$\mathrm{D}=\mathrm{D}_{\mathrm{o}}-\mathrm{A} \cdot \mathrm{t}^{\mathrm{n}}$

where $D$ and $D_{o}$ is the mean grain dimension for $t$ and $t=O$ times respectively, $\mathrm{A}$ and $\mathrm{n}$ are constants, $\mathrm{n}$ being much smaller than 1 .

In view of the inversely proportional dependence of resistivity on the grain diameter, the resistance will also exhibit a similar type of variation.

$$
\frac{\Delta \mathrm{R}}{\mathrm{R}}=\mathrm{B} \cdot \mathrm{t}^{\mathrm{n}}
$$

where $\mathrm{B}$ is a constant.

The chromium on the other hand diffusing into the nickel film causes an increase in the number of scattering centres and thus the free path decrease. This results in an increase in the resistance $R$ as well as a decrease in TCR.

The changes of both of these mechanisms compensate to some extent. The degree of compensation varies with temperature and time while the changes of resistance and those of the TCR coefficient are closely correlated. At low temperatures (below $500 \mathrm{~K}$ ) the effect of recrystallization predominates, whereas, at higher temperatures it is the effect of diffusion that predominates.

Of essential importance is the thickness of films of $\mathrm{NiCr}$ and $\mathrm{Ni}$. With a thick film of $\mathrm{NiCr}$ the diffusion effect of $\mathrm{Cr}$ is greater, whereas with an increase in the thickness of nickel films, the effect of recrystallization also increases.

In case of catastrophic failure a break in the current path occurs most frequently at an overheated point due to the melting of the film and electromigration. The damage may also take place as a result of any crack in the film or substrate ${ }^{8,9}$. These processes may have an important effect at considerably increased temperatures of the sen- 
sor, i.e. above $673 \mathrm{~K}$. At temperatures below $523 \mathrm{~K}$ the result of this phenomenon is insignificant.

\section{CONCLUSION}

The nickel films $0.5 \mu \mathrm{m}$ to $5 \mu \mathrm{m}$ thick protected by an oxide film exhibit useful parameters and thus can be used for constructing thermoresistive sensors. They have a high TCR and a good stability with time. As a result of their effect on stability and life-time the appropriate selection of the thickness of $\mathrm{NiCr}$ and $\mathrm{Ni}$ films is of essential importance.

\section{REFERENCES}

1. F. Thieme and W. Kiestein, "Influence of grain boundaries on the electrical resistivity of thin polycrystalline films: a correlation between the Mayadas-Shatzkes and the Wissmann-Welder equations", Thin Solid Films, 30, 371-375 (1975).

2. C.R. Tellier and A.J. Tosser, "Approximate expression for the electrical resistivity of thin polycrystalline metallic films", Thin Solid Films, 35, L19-L26 (1976).

3. Corning Material Information, Publication Data, March 1977.

4. A.D. Kraus, "Cooling electronic equipment", University of South Florida, Tampa, Florida (1956).

5. Awatar Singh, "Film thickness and grain size diameter dependence on temperature coefficient of resistance of thin metal films", Appl. Phys., 4, 1908-1909 (1974).

6. E.J. Tochitski and A.M. Chaplanou, "Annealing behaviour of polycrystalline metal films", Thin Solid Films, 32, 213-215 (1976).

7. V. Stary and K. Sefcik, "Electrical resistivity and structure of thin nickel films effect of annealing", Vacuum, 31, no 8/9, 345-349 (1981).

8. R.R. Zito, "Failure of reflective metal coating by cracking", Thin Solid Films, 87, 87-95 (1982)

9. T.M. Berlicki, M. Btasiak and E.L. Prociów, "Nickel thin film thermoresistive sensors", Proc. 4th European Hybrid Microelectronic Conference (Copenhagen, May 1983), 178-183 (1983). 

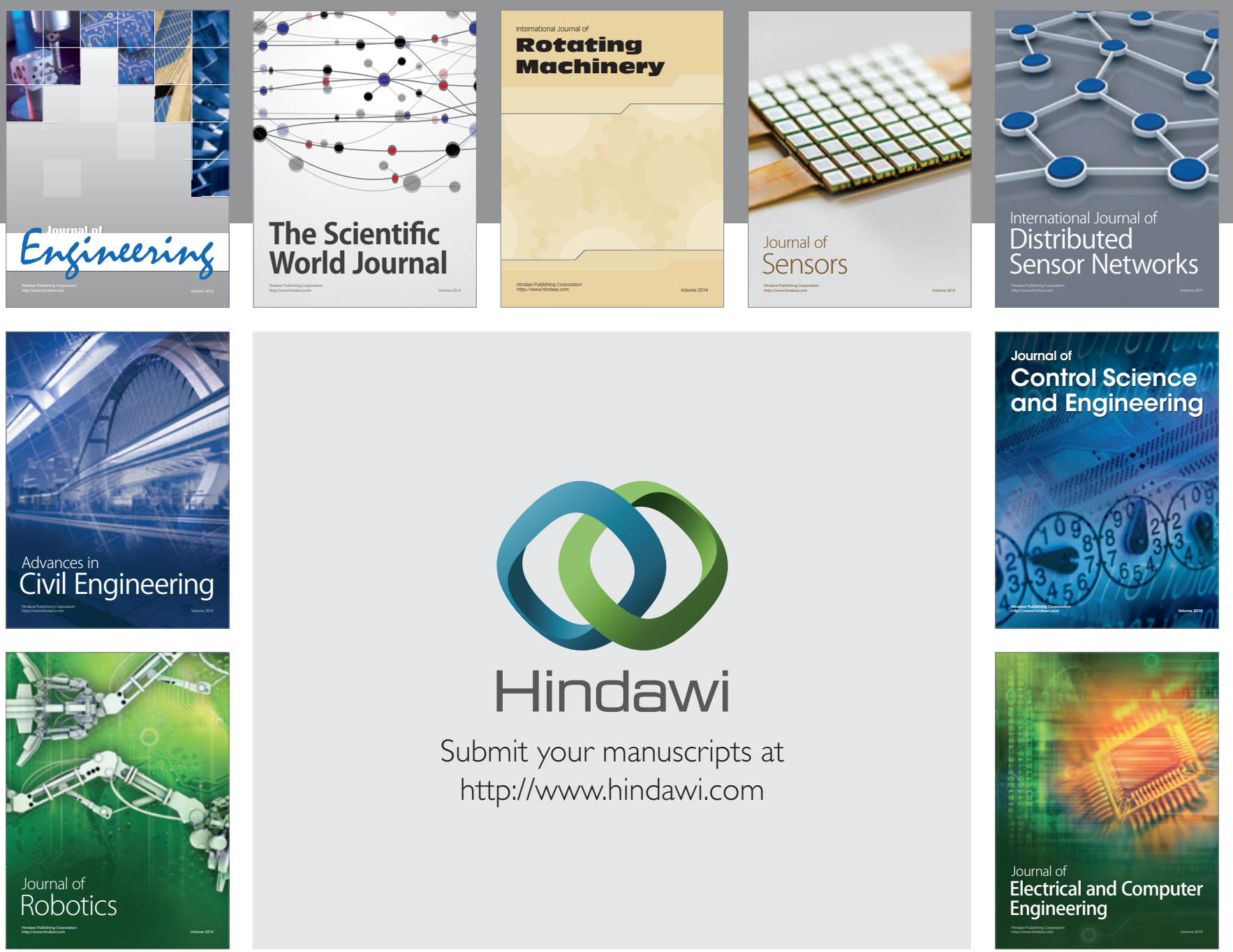

Submit your manuscripts at

http://www.hindawi.com
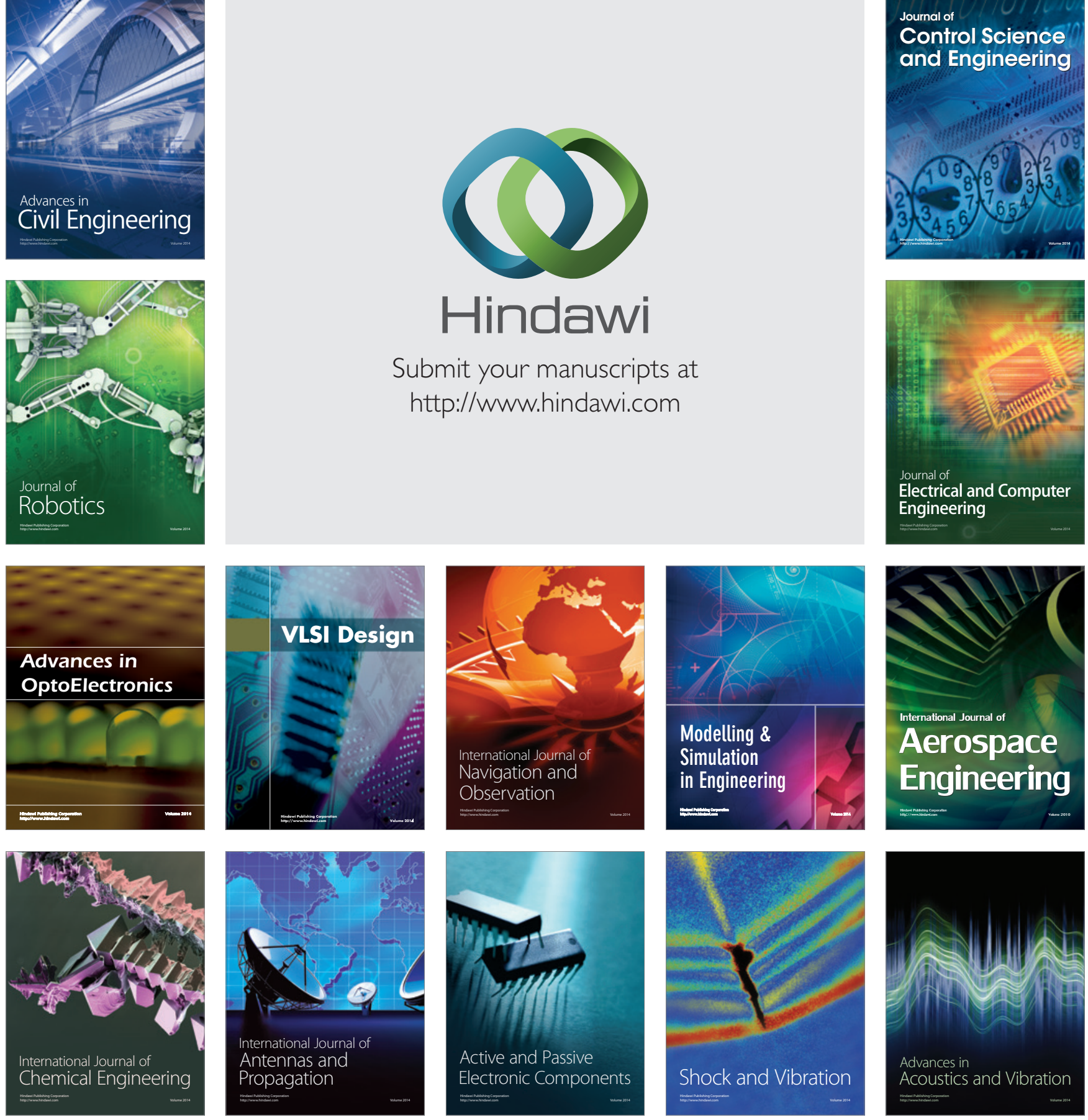